\title{
Attachments to Participatory Digital Infrastructures in the Cultural Heritage Sector
}

\author{
Dagny Stuedahl \\ Oslo and Akershus University College of Applied Sciences, Norway / dagny.stuedahl@hioa.no
}

Mari Runardotter

Luleå University of Technology, Sweden

Christina Mörtberg

Linneaus University, Sweden

\begin{abstract}
This paper explores knowledge infrastructures developed with the aim of opening cultural heritage institutions for public access and involvement. We concentrate on the new modes of knowledge production of professionals and amateur experts involved in the design and use of open archives and wiki communities as a part of transformations towards participatory digital public infrastructures. Ideas of crowdsourcing, policies of open data and engagements in community-based cultural heritage influence participants' visions of future ways of generating, sharing and maintaining their knowledge. The paper identifies how the concept of attachments may help us analytically to understand the dynamics of multiple situated knowledges that are played out when people embrace digital technologies and open-data policies to connect past, present and future orientation of cultural heritage engagements.
\end{abstract}

Keywords: knowledge infrastructuring, attachments, future orientation

\section{Introduction}

The ideas of citizen participation, crowd-sourcing and open data currently receive significant attention from businesses, policymakers, public sector organizations and authorities. The commons movement has drawn interest from the cultural sector, offering new economic, cultural and social models of self-organization and joint activities (Economics and the Common(s), 2013; Hess, 2008; Botero et al., 2012; Björgvinsson, 2014). The emerg- ing interest in open data, crowd-sourcing, and distributed collaboration can be connected to a heightened attention towards social aspects of knowledge sharing, which includes the material, technical and political aspects of how knowledge production is being transformed within a digital cultural heritage paradigm shift (Stuedahl, 2009). It becomes central to understand how ideas of participatory and radical openness are being con- 
figured to fit the rapid technology development that is a part of these knowledge infrastructure transformations. We will here focus on how archivists and local historians build on sources and resources from their disciplinary pasts to meet with the present demands and desired futures of open data.

E-government ideals have developed in parallel with the ideas of citizen participation, and open data. The Public Sector Information Directive (PSI Directive) began in 2003 with the goal of actively implementing policies for open data. In 2009 the European Commission stated that, despite progress, there were still barriers hampering the cross-border use of public sector information (COM, 2011b). To advance the market and open up services based on public sector information, the PSI directive has been updated several times (COM, 2011a; COM, 2011b; Directive 2003/98/ EC, 2003; Vickery, 2011). The revised PSI Directive includes re-use rules and norms for machinereadable formats and states that governmental agencies should apply open data policies, thereby making data and information available for re-use by businesses, researchers and developers (PSI directive, 2013). As such, open data could constitute a means for infrastructuring an open government. The PSI directive expresses what is to be achieved, but how to actually implement open data and how open data would involve the public in practice, are not touched upon.

Understanding the diverse movements of open data, transparency and citizen participation require a focus on how knowledge infrastructures are enacted in everyday practices where people shape the specific knowledge that keeps institutions together. Knowledge infrastructures are defined as "robust networks of people, artifacts, and institutions that generate, share, and maintain specific knowledge about the human and natural worlds" (Edwards, 2010: 19, Edwards et al 2013). Ever-changing processes of relations, making and practising (Bowker, 1994) prompt a shift to understanding 'infrastructuring' as a verb (Karasti \& Syrjänen, 2004; Karasti \& Baker, 2004; Star \& Bowker, 2002), opening up temporal perspectives for examination. Infrastructuring includes awareness of the procedural (Pipek \& Wulf 2009; Bossen \& Markussen 2010), and long-term and open-ended processes of continuous co-creation (Ehn, 2008; Björgvinsson et al. 2012; Hillgren et al. 2011; Le Dantec \& Di Salvo 2013). These temporal dimensions give a quality of constant 'becoming' to infrastructuring (Karasti \& Syrjänen, 2004). As a concept capturing the temporal dimensions of infrastructuring 'the long now' (Edwards et al., 2009; Ribes \& Finholt, 2009) has been suggested to point to the long-term dynamics of aligning end goals, motivating contribution and designing for use. This concept focuses on the time scales of actions, and concentrates on the relations and tensions between present demands and a desired future as central for infrastructuring.

This paper argues that this focus on scales of actions between present and desired futures gives an overly limited perspective on what it takes to change knowledge. We argue that knowledge infrastructuring also involves situated knowledge and historical traces and patterns of practices connected to the past, which if not given attention cause simple understanding of tensions. There are currently many expectation and myths (Hellberg \& Hedström, 2014) of the positive social impacts of open data. The uptake of open data meanwhile goes slowly, and "the level of knowledge and understanding of open data is currently rather low, and most data producers don't yet see the potential benefits" (Halonen, 2012: 10). There is a resistance to use open data in practice. What if we understand this in relation to the past experience and knowledge that data producers bring to infrastructuring processes? What would a time scale of a longue dureé (Braudel, 1958) including historical time and connections to past knowledge and conceptions of quality bring to knowledge infrastructuring studies?

We apply the concept of attachments to bring attention to how people's change of practices influence the evolution of knowledge infrastructures over time. Our special interest is in how situated knowledge (Haraway, 1988) may influence knowledge infrastructure processes aimed at openness in the cultural heritage field and how we can understand this from a humanistic perspective on time scales. Attachments point to aspects of knowledge that are not related to content of knowledge, but to value concerns, familiarity and imaginings that may influence 
infrastructuring (Gomart \& Hennion, 1999). In particular, we focus on the role of attachments to existing infrastructuring knowledge practices, standards and values producing tensions with ideas of open, participative and crowdsourced heritage information and resources. Our interest in attachment is based on how this concept may help us reveal how time, especially scales of past, present and future, influence knowledge infrastructuring.

\section{Addressing Attachments in Knowledge Infrastructuring}

With the enrolment of attachments we will explore how the complex and multiscale relations and scopes of knowledge infrastructuring are not only about local and situated, global and pervasive, social-material or technological arrangements, but also about scales between past, present and future. 'Attachments' are mechanisms that act as both sources and resources for how people engage, and move between internal motivations and external determinations of knowledge and experience (Gomart \& Hennion, 1999; Latour, 1999; Hennion, 2012). The concept of 'attachments' is used in various disciplines: within STS studies, to explore material and social aspects that influence actors in for example public involvement processes (Gomart \& Hennion, 1999; Marres, 2007); and within the pragmatist view of Actor-network theory, as a vague and indefinite concept of what holds the social together (Hennion, 2012). It has been suggested as a means to focus on "that which lets/makes happen", giving awareness of passion influencing actions (Greimas \& Courtés, 1986, in Gomart \& Hennion, 1999). Thus the concept points to entities that are not the content of actions but become apparent in experiences and in people's knowledge practice (Hennion, 2012).

However, the concept has also been used for alternative forms of analysis. In psychology, attachments point to the ties of affection that bind mother and child and endure over time. Another definition is as a distinct unit that adds a function to the thing to which it is connected, in much the same way as the attached document adds a function to an email. In design studies examining the constitution of public, attachments have been used to pay attention to the pragmatic dynamics and fluid social alignments between participants and authorities (Le Dantec \& Di Salvo, 2013). Here attachment is applied to capture how sources and resources build 'dependency on' and 'commitment to'.

These affective and pragmatic dynamics of attachments go beyond the articulation work found in earlier infrastructuring studies (i.e. Fujimura, 1987; Strauss, 1988, 1993; Schmidt \& Bannon, 1992; Grinter, 1996) focusing on technical and organizational arrangements, and coordination of cooperative work. Also the extended understanding of articulation work as communication and coordination mechanisms, focusing on language and category formation (Baker \& Millerand, 2007), may overlook sources that pose their presence in people's knowledge practices before articulation. Attachments thus provide us with an opportunity to explore entities that are not facts, causalities or reasons but that still have an impact on knowledge infrastructuring. Attachments are both sources and resources for people's agency and knowledge, and direct attention beyond intentions, to entities that do not belong to the vocabulary of action.

Knowledge is attributed to a wide variety of properties and domains, and includes static knowledge of facts, concepts or principles as well as knowledge about valid actions and manipulations within a domain (de Jong \& FergusonHessler, 1996). This knowledge-in-use is discussed within both educational and science studies, and serves in both to capture how knowledge is constructed. But, they differ in understanding knowledge as acting on, as opposed to knowledge as actually made (Haraway, 1988). The concept of situated knowledges is used for the knowledge needed to understand situations and to describe how knowledge is partial and situated in local and cultural practices. It is within this understanding of situated knowledges that attachments sit, as entities situated in local and cultural knowledge practices that work as sources and resources for knowledge in the making.

Envisioning the future is relevant for the making of knowledge in the present. Attachments as 'that which lets/makes happen' are also related 
to how people, in innovation processes, activate knowledge and position themselves in relation to an envisioned future. Thus, transformative knowledge infrastructuring involves re-thinking and re-conceptualizing existing factual knowledge and situated knowledges that have strong relations to the past. While these aspects are sometimes difficult to articulate, some of them might even be tacit: they are attached to how people use their knowledge in transformation processes. Thus, our focus on attachments maps how people experience functions and relations that appear in knowledge infrastructural changes in archives and in cultural heritage communities. This paper explores how attachments are rooted in obligations stemming from the past, which still permeate the present, and how these are related to conceptions of quality in the present and in the future.

\section{Open Cultural Heritage?}

The idea of 'open' libraries, archives and museums (LAM) in policy, are highly influenced by the commons movement (Lessig, 2004), where sharing, use and re-use of cultural heritage objects change the focus of these institutions from giving access to cultural heritage into being concerned with how to actively involve the public - or the crowd. Consequently, the concepts of openness and open data are based on the same ideas of public participation as in regulations of digital services delivered by public organizations (Lathrop \& Ruma, 2010).

In archives, practices are already distributed and diffuse, and closely related to sets of specialized archival technologies and indexes, which define knowledge in ways that contradict diversity (Bowker, 2005). Meanwhile, archival concepts and practices are transformed radically through technological development - for example, changing conceptions of permanence and stability (Røssaak, 2011). In other words, our contribution to understanding of "the long now" of infrastructuring as implying that long term sustainability requires consideration in the present (Ribes \& Finholt, 2009), is the additional consideration of the past. The requirements of transparency, democracy and openness of archives also involve a move towards exposing the contingencies, framing, reflexivity and the politics embedded in these archival technologies (Waterton C, 2010). This infrastructuring aiming at openness and public involvement may cause friction between technological aspects and knowledge practices (Van Passel \& Rigole, 2014; Holdgaard \& Klastrup, 2014; Perkin, 2010). For example, open cultural heritage initiatives do not only give institutions the options of involving the crowd in, for example, classification, transcription and organization of content (Owens, 2013; Oomen \& Arroyo, 2011; Stevens et al. 2010), they also force institutions to re-think archival practices. It becomes necessary to include routines of responding to public users of archival material, and to make space for public contribution and comments on categorizations of archival content. Thus, emerging forms of knowledge practices between archives and the public include re-thinking contextualized relations (Star \& Ruhleder, 1994, 1996) and translating current imbrications of formal and informal, ill-structured and well-structured, standardized and 'wild' practice. As such, archives are interesting sites for studying infrastructuring since "information, lived experience and infrastructures" (Star, 2010: 614) are at the centre of their knowledge practices. Focusing on attachments might reveal how conventions of practice emerge and how people negotiate existing dependencies and commitments.

Our approach to infrastructuring for openness, open data, public involvement and crowd participation is concerned with the interpretations that professionals and amateurs make, and how they find ways to realize a new openness within the framework of existing practices of their local institution. We explore infrastructures "in the making" (Bowker et al., 2010) in two different contexts and phases: a startup phase and the implementation phase. Our focus is on how people align envisioned future infrastructural relations with present understanding of what openness involves for their work practice. This affects their translations and engagement, and influences the development of new knowledge-infrastructural relations when technologies change. We present stories from two different case studies drawn from cultural heritage institutions: an archival institution and a 
NGO-based local history community. Both groups need to change their knowledge practices when Web 2.0 and 3.0 and social-media-based applications introduce directions and expectations of participation. The two stories exemplify how infrastructuring towards openness and public involvement challenges library, archives and museum (LAM) institutions by introducing new forms of entanglements with the public.

The two stories are about two groups of experts: professional archivists and amateur local historians with shared interests in historical and memory material such as records, photo archives, personal letters, etc. Their knowledge infrastructures and practices differ. Archivists have traditionally concentrated on institutional processes of collecting, preservation and dissemination of historical material; their point of departure is the archive as repository. The local history community works with interpretations and re-presentations of archival material in physical publications. We study how such people imagine potential futures for the norms, practices and routines that they presently share when working to realize a future open and participatory cultural heritage. This informs our understanding that knowledge infrastructuring includes imaginations of the future as well as forms of making and practicing developed from the past. Thus, we ask what attachments people in cultural heritage institutions have to infrastructures of digital heritage participation and open data. How are these attachments related to knowledge and conception of quality connecting to the past? How do these attachments create tension in knowledge infrastructuring processes?

\section{Methodological Approach}

We approach these questions with an interdisciplinary collaboration between cultural studies and informatics based on our joint analysis of different research projects in two different Scandinavian countries. The Swedish case is a design project in its start-up phase, focused on translations of the PSI directive, and was especially focused on the way professionals in archives interpret and implement the PSI open data principles in the design of a citizen-centric e-service in archives. This case describes the early stages of knowledge infrastructuring, where people are working hard to translate the directive in relation to existing archival systems. This we define as infrastructuring from above. The Norwegian case of the local history NGO focuses on how local historians convert their writing to a wiki platform. Special attention is paid to how a community re-organize their collaboration, coordination and re-thinking local history genres of writing when using the opportunities of social technologies. We consider the latter as infrastructuring from below involving a knowledge-infrastructuring process where the community has already taken the wiki platform as the premise, and we focus on their handling of the new possibilities and constraints caused by this platform. Thus, the two cases represent two scales of infrastructuring processes and differ in how far the infrastructuring towards openness has been implemented. The Swedish case tells the story of infrastructure in the making from the angle of negotiations in design processes where openness is to be defined and technologies developed to support it. The Norwegian case tells a story about how making involves ongoing configurations in use despite the technological structure in place. The two cases also exemplify two scopes of infrastructuring: the Swedish case is closely directed by policy; the Norwegian case is based on community negotiations related to evolving commitments and dependencies.

The two cases of infrastructuring from above and from below require research methods that capture empirical material to give an understanding of how the infrastructuring processes are experienced differently in different phases. We focus beyond the moments and points of infrastructuring processes where infrastructures become visible or break down (Karasti, 2014). Our aim is to study the formations of infrastructuring, and both studies are based on ethnographic approaches focusing on the infrastructuring as processes of 'becoming', where people build on every-day practices and knowledge "where a need for continuity mandates that new forms emerge through juxtapositions and connections with existing forms" (Karasti, 2014: 2).

The cases have been studied using different methods and introduce different methodological concerns. The Swedish study is based on 
ethnography of the design process to "facilitate communication and [as] a vehicle for producing information relevant for the design of new products" (Mörtberg et al., 2010: 108). The study is based on participant observation, field diaries and document analysis, and an analytical sensibility towards invisibility of knowledge and experiences, in order to obtain understanding and find ways to integrate and articulate this in technology design (Karasti, 2001, 2003). The study identifies the trajectories of discussion themes and decisions made in the design process, and how these are related to interpretations of directives from policy documents. The study of the Norwegian wiki-community, meanwhile, aims to capture the ongoing infrastructuring in an already-established technical structure. This is based on the principle of not exaggerating the difference between virtual and other settings relevant for the infrastructuring work suggested by virtual ethnography methods (Hine, 2000, 2005). The study focuses on the lived online activity of the community and its connection to offline social spheres (Hine, 2005). Of special concern is how the given technical structure of wikipedia affects or is affected by the transfer from face-to-face community work to online collaboration. This study is based on awareness that online community observations are partial visits into preexisting processes where isolable and describable locales and cultures are impossible (Hine, 2000), thus including online studies in combination with semi-structured face-to-face interviews. The online ethnography of the wiki-activities concentrated on the discussions connected to writing articles, and followed, from June 2010 till 2012, a thread in the discussion forum connected to one article that had evolved over a long time span. The semi-structured group interview lasted 1.5 hours with 5 staff members of the wiki administration from the institute, including two administrators. The interview was transcribed, and the first publication (Stuedahl, 2011) was shared with the institute and commented upon by the staff members.

In the next subsection we describe two narratives from the case studies, and then we discuss methodological considerations, given that the two studies are based on different disciplinary approaches and scholarly traditions. We then discuss the relevance of the concept of attachments in relation to the case studies and to STS-based studies on public involvement relevant for the activities of infrastructuring for open cultural heritage. We end with a discussion on infrastructuring processes, and how infrastructuring may also contain dimensions of potential future consequences of choices made today, interpreted with knowledge that has cumulated from the past.

\section{Story 1: Infrastructuring the Crowdsourced Archives}

The story of the You! Enhance Access to History (YEAH) project can be viewed in terms of the relation between infrastructuring and organizational change (Star \& Ruhleder, 1996), and how the issue of creating open cultural heritage data and semantic linking initially was left to the archivist (Runardotter et al., 2011). This project was preceded by the Access to Public Information (APIS) project, 2010-2011, in which the intention was to clarify a research idea and build a network for carrying out a research and development project. The same people formed the project team in both projects: seven people from three National Archives, one from an SME and two researchers from the university, one of whom functioned as project leader, and is also co-author of this paper. In the APIS project there was agreement to collaborate and coordinate material from the LAM sector, and through this to offer citizens re-designed, new and innovative cultural heritage digital services. The APIS project explored the preconditions for creating border-crossing digital services based on archival material by conducting a comprehensive investigation of the area (Runardotter, 2011; Runardotter et al., 2011). Further, it was a collaborative design project with team members from different disciplines. This implies that "different discipline interests [were] brought to the table by each participant" (Baker et al., 2005: 4). Moreover, once agreement on what to accomplish was reached, the design project continued with design activities, such as sketching and modelling and resulted in a demonstrator as a kind of prototype (Bødker et al., 2004). Hence, for participants 
to reach agreement on a theoretical, abstract level was not problematic.

The YEAH project gained funding in 2011 to address public sector services and their impact on today's society. It set out to focus on public information in archives and citizens' access to it. More specifically, the project aimed to design a prototype of a citizen-centric e-service and explore the role of crowdsourcing methods for augmenting archival e-services with improved access to and usability of archived information. The project team also agreed to design the e-service following three main criteria: it would be citizen-centric, generic and border-crossing. ${ }^{1}$ This implied that it would be developed in close collaboration with end-users, building on their needs, requirements and visions, and also through collaboration between different stakeholders (citizens, archives, universities, IT developers, and service providers) and, finally, that the developed e-service should be of interest internationally.

The project members work in public organizations that are distinguished by characteristics such as rational rules and procedures; these organizations have structured hierarchies with formalized decision-making processes and their personnel often advance based on administrative expertise (Parker \& Bradley, 2000). These organizations are also subject to political control (in contrast to market control) and therefore cannot be compared with the private sector, since underlying political ideologies influence public organizations' productive activities (Parker \& Bradley, 2000). The YEAH project aimed at an e-service in line with intentions stemming from policies around open government and open data, and therefore emphasized the use of ICT in accordance with the European eGovernment Action plan - to help public organizations deliver services to citizens in smart and innovative ways (COM, 2010). As part of knowledge infrastructuring, translations of these policy intentions to the knowledge practices of the National Archives context were needed for the project team to be able to build a prototype that fulfilled the aims, and was in line with the PSI directive.

The YEAH project ran between December 2011 to April 2014. In total the project carried out 32 project meetings, 15 during 2012, 12 during 2013, and 5 during 2013. On 18 January 2012, the project team agreed to aim at "enhancing descriptions of digital objects in existing archival collections by crowdsourcing, in order to improve the description of archival material as well as to improve access to the same".2 However, public involvement and crowdsourcing was debated among project team members, whose commitment to their professional role and mission became visible in their concern over what this might involve. The discussions continued from January to October 2012 and additional themes, besides crowdsourcing, included whether the archival subject ontology or 'Keywording system' is too complicated for the crowd (that is, any citizen), ${ }^{3}$ what if, in using crowdsourcing, the wrong or poor quality information is added (e.g. if wrong person is tagged or if two persons have the same name); ${ }^{4}$ how to integrate or link to information created by the crowd with the archival catalogue system ${ }^{5}$. Finally, the decision was taken that the project would develop a framework (demonstrator and guidance) for any memory institution to open their data and link their cultural heritage information to the semantic web. ${ }^{6}$

A central recurrent theme was related to the question of the possible result of citizenproduced material. Issues like "what happens if we let the citizens ' in' and allow them to contribute to our collections" produced a hesitancy towards openness at every monthly meeting from January to June 2012. Another theme was how quality was to be ensured and how quality could be checked when citizens added data, and what could happen if the added information was incorrect. The unpredictability of how crowd-sourced activities and production of content would influence the archival holdings was of great concern to archivists. This gives an insight into how public organizations may be hesitant about new requirements (Kellogg et al., 2006), and highlights how this is connected to the uncertain consequences of crowdsourcing.

As a result, the team decided to review reported experiences of crowdsourced archival material. By June 2012 the project team also reasoned that it would be difficult to make innovative contributions to the LAM communities through crowdsourcing, arguing that "so many crowdsourcing 
projects have already taken place." ${ }^{17}$ This argument shows their main commitment to their own, local organization and community rather than concern for citizen-centric perspectives in themselves. The project team had difficulties figuring out what this project could contribute through crowdsourcing, and also showed uncertainty about whether crowdsourcing was in line with the regulations of open data, as well as how public involvement should happen. Instead, the project team defined their focus in the project as linking open data, and defined this as more interesting and valuable for citizens as an initiative towards openness because of its potential to enhance the experience of cultural heritage data. Consequently, the meeting in October $2012^{8}$ was dedicated to investigating the technical aspects of linked open data, defining the type of archival data the project would work with and how to link it, and how to find a partner with expertise in linking open data. This shift of focus shows how crowdsourcing potentially challenges archival institutions more than Linked Open Data and, since the actual opening of institutional data is still in the hands of the archives holding that data, their feeling of control over future consequences and quality of the content are an important factor in infrastructuring crowdsourced and participatory archives.

Still, it was not until March $2013^{9}$ that the team finally reached a common understanding of what to achieve in the project, and there was agreement on the result of the project: the aim should be to develop 'a demonstrator for any memory institutions to open up their data and link their cultural heritage information to the semantic web.' Decisions were made to focus on genealogists as a representative group of citizens, and to limit the material to be considered. In this way, the project team was able to find a compromise that was acceptable for the project members, as it decreased fear of uncontrolled, or messy, collections in the future. The project ended up with providing a simple methodology to annotate relevant holdings and wrote a methodology handbook on how to create cultural heritage open data and link it to the semantic web. ${ }^{10}$ The project ended in April 2014.

The case shows how archivists have several attachments to implementation of openness, and ideas of archives to 'open up' and let data 'out' and citizens 'in'. Several of them are related to the possible everyday consequences of this openness: the accuracy of the data, whether information added by citizens is correct (true), but also to changes in the responsibility for the archival collections and the concern that they are kept in order. In the end, the project turned from a citizen-centric and crowdsourcing involvement initiative towards an inter- and intra-organizational approach that would create less change in the present local-knowledge infrastructure. The eventual form of the policy-driven, and thereby intended, organizational change aiming at openness shows how the archival infrastructure may be challenged when policy requirements for openness meet with interpretations of local- and everyday situated practice.

\section{Attachments to Infrastructuring from Above}

The archive story gives an example of how the PSI directive has numerous implications for the cultural heritage sector (COM 2011a; 2011b; Directive 2003/98/EC; Vickery, 2011). In short, the directive is in line with policy goals aiming at an openness that is expected to facilitate democratic processes of the knowledge society, and increase innovation and development of new or improved digital services. This includes expectations of increased productivity and improved effectiveness, efficiency, information quality, interaction mechanisms, better governance tools, and improved government coordination and collaboration (Andersen, 2006; Andersen et al., 2005; Gauld et al., 2009; Grönlund \& Ranerup, 2001; Lathrop \& Ruma, 2010; Sefyrin \& Mörtberg, 2009; Stoltzfus, 2005).

The story tells how knowledge infrastructuring towards crowdsourced archives, following the PSI directive for re-use of public sector information, collides with existing infrastructure relations. Crowdsourcing and public involvement was defined as a less interesting contribution, because it was perceived as less controllable than linked open data. The case underpins the role of attachments for infrastructuring towards openness, and how they are based on professionals' conceptions of control and quality gained from present and local knowledge practices. 
In the YEAH project we identify the attachments of hesitancy and unpredictability. These are attachments of a social kind, and can be related to the material attachment of the provenance principle. The principle is fundamental to the careful separation of archives and arrangement according to the original order of the archival collection. The provenance principle is therefore about the importance of knowing where a document was created, by what process, to what end, for whom, when, and how it ended up in the archives (Dollar, 1992). It is important for archives to be able to guarantee the trustworthiness and quality of the information held, as well as making sure that the information is structured and ordered. In the YEAH project, the provenance principle is an attachment from the past that influences knowledge infrastructuring that aims at the future. The reason for holding archives, the preservation of societal memory, relies on this intention of making archives accessible. The intentions of openness in the knowledge infrastructuring had to be scrutinized because of this attachment.

The attachments here were closely related to interpretations of openness in the PSI regulation as related to opening for crowdsourced data, but these attachments did not cause direct actions. Instead they triggered the need for sorting out what openness really means for archives. The translations were multiple; some were hard to grasp, and thus the translations represented an important part of the project narrative. Without common agreement, the project members would not have been able to carry out the design project as intended. It appears that, in order to make progress when infrastructuring, there is a need to make visible and discuss the attachments that people bring along when envisioning the future. Until these are dealt with, it is likely that the people involved will show reluctance, hesitancy and concern. In other words, attachments might be obstacles that hinder development and progress.

Our first story has followed knowledge infrastructuring from above aiming at openness of heritage institutions and in relation to a design project related to the PSI directives of openness. We will now turn to a story of infrastructuring from below from a community-based wiki involving both professional and amateur experts of local history.

\section{Story 2: Infrastructuring in the community based wiki}

The lokalhistoriewiki.no was launched by the Norwegian Institute of Local History (NILH) in 2008 after a longer process of trying to implement technology to enhance community activities. The institute is an independent NGO founded in 1955 by the Norwegian Ministry of Culture with the aim of stimulating engagement in local history, and it assembles communities of local history, memory and genealogy (Alsvik, 1993). In 2003 the institute opened a website thought of as a site for collaboration with and between the different communities of amateur and professional local historians connected to the institute. In 2006 they started an online network space for local history projects, aimed at stimulating the sharing of methodological solutions and practical problem-solving of writing local history. However, this initiative ended up being a one-way interaction: the institute serving other institutions, organizations and people. The idea of creating a participatory local history wiki was proposed by members of the Wikipedia community and the institute could see the potential of the wiki format as a solution to connect local historians across different communities and, in addition, assemble the emerging number of local history lexica online. When we approached the project lokalhistoriewiki.no in 2010, the wiki had been up for two years and contained enough online material, articles and forum entries to serve as an object for online ethnographic observations.

Participating in the wiki requires that users register as identified individuals. The wiki-collaboration is supported by four 'bureaucrats' from the Institute of Local History constituting the wiki administration in collaboration with 17 'administrators' and 12 'vocational supervisors' recruited from both the Wikipedia community and local communities of amateur historians. The 'administrators' have defined roles for sorting out categories and entries, helping new users get started and following up on new publications in the wiki. They have access rights to delete or re-publish pages, they can lock pages, block individual users, edit 


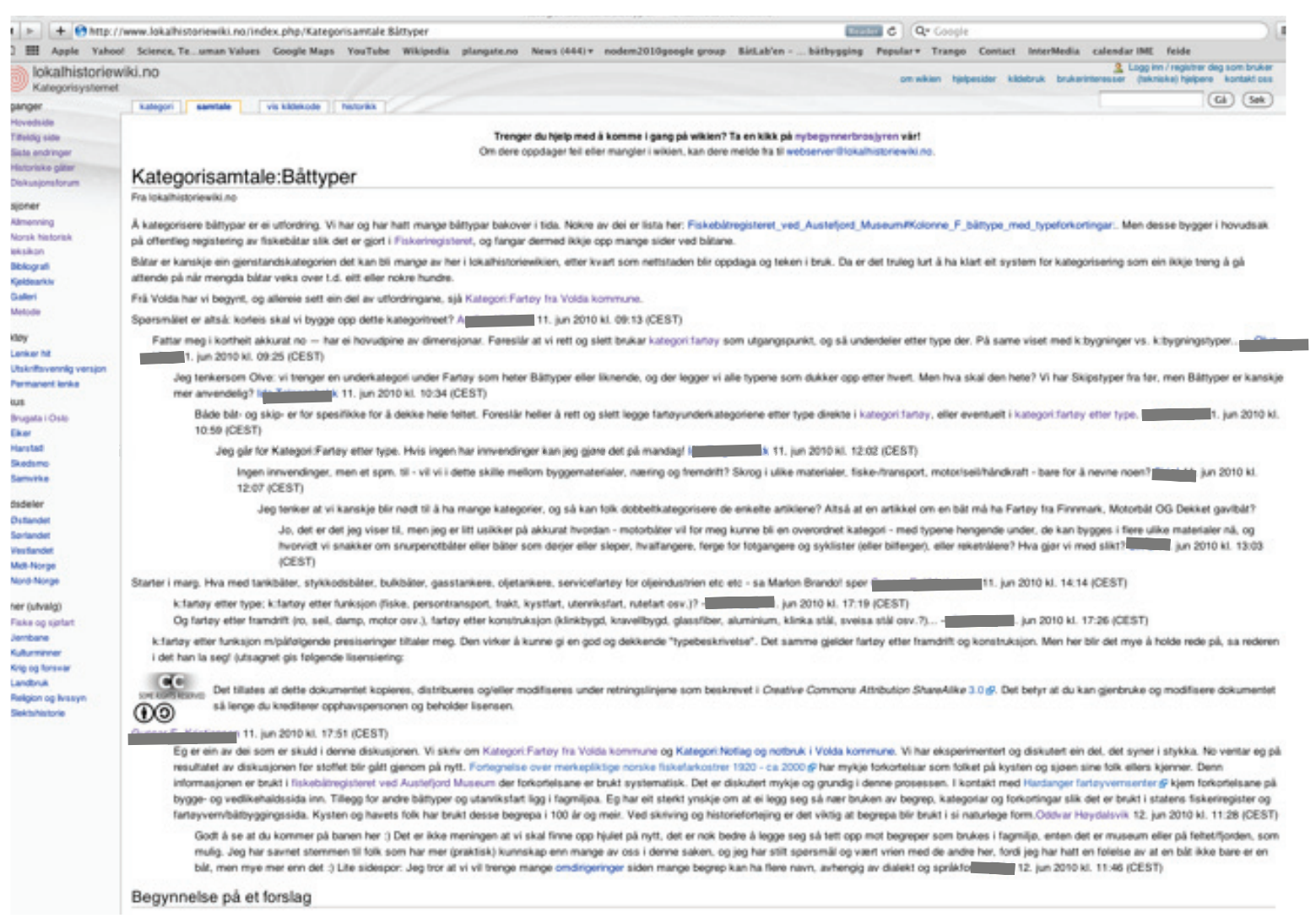

Figure 1. In the discussion forum opinions are shared about whether formal or informal categorization makes the wiki most solid, findable and durable over time.

messages and import pages from other wikis. Thus the 'administrators' have a double role as both technical and administrative gatekeepers, and their responsibilities contain both technical and systemic challenges as well as professional evaluations. The 'vocational supervisors' have the role of checking that the articles meet criteria of proficiency, helping users with methodical questions, defining source qualities, sorting out licence questions and answering questions concerning editing or closing pages.

We focus here on how the co-construction of concepts and categories that structure the wiki space evolve. From the discussion forum we have chosen an excerpt from 10-18 June 2010 in which professionals and amateur historians negotiate on establishing a hierarchy of categories for entries and articles on ships, boats and marine vessels. We render the discussion from the thread (see figure 1) in the form of a narrative in order to add relevant contextual information on the trajectory.
This discussion thread was started by one of the professional historians and vocational supervisors, who claimed that categorizing boat types is challenging because the formal categories are built on the registration systems provided by the Directorate of Fisheries, which neglects all the historical boats and vessels in the Norwegian coastal heritage tradition. The participant, anonymized as AK, state the need to make a system of categories that does not need to be reorganized in the future. A group of marine historians from the west coast of Norway has in collaboration with the coastal museum created a structure of categories that builds on a classification system for recording traditional fishing boats in the region. AK provides a hyperlink to their work as a proposal to start the discussion and further argues that this structure embraces information about local occurrences, formal categorization, attribution, name of the boat related to form and function, type of boat, materials used in construction, date, size, volume, name, date of motor, etc. In this way the structure 
captures both the material and the functional aspects of the boat in question and contains 15 subcategories to be used in the categorizing of boats.

The administrator representing the Wikipedia community, OU, immediately responded to AK's request and argued that the category system could be built in much simpler ways. OU suggests that marine vessels might be the main category, and then subcategories built on type and function. OU tries to keep the number of categories at a manageable level. After some discussion, OU suggests categorizing the vessels by type. As a response, another member of the community points to the many vessels characterized by their functions (cargo-ships, oil-tanks, service-ships) and that categorization by type only would not cover these. OU proposes categorizing vessels by function, progress and construction.

The next day, $\mathrm{OH}$, a member of the community connected to a museum on the west coast and an active amateur-expert in marine history, suggests a structure of categories that is familiar to people on the coast as well as in maritime communities. $\mathrm{OH}$ points out that the index developed by the governmental register is based on wellknown acronyms used for more than 100 years, and that these indexes are integrated in the category system at the coastal museum. OH asks whether the category system on the wiki could be developed in correspondence to this well-known category systems - because in writing and storytelling it will be important that the concepts are used in their natural form.

Four days later a member of the wiki administration, IT, starts to build a proposed category three based on type, function, material and construction. This is responded to by $\AA$, who suggests a category denoting the visual form of the boat, observing that categories such as function, material, and construction could provide structure, but might neglect the traditional open boats of Norwegian maritime history. $\AA$ ends by pointing out that the wiki should be developed in accordance with a normal thesaurus - and that it is important to clarify this early in the creation of the wiki-structure.

On 16 June, IT asks if the categorizing could start at a more basic level, solely with vessels, and that the category system could be extended gradually when the needs of the wiki community's become more obvious. Collaborator $\AA$ answers by asking if it would be fruitful to build the structure of the wiki in relation to concepts used by formal institutions like the Directorate for Cultural Heritage and The Cultural Heritage Act. These use two different categories, separating vessels and boats. The discussion thread ends November 2010, when the administrator IT ask if vessel could be the main category and the sub-categories could be type, use, materials, construction and rig.

\section{Attachments to Infrastructuring from Below}

The participants in this wiki-thread are in fact discussing different attachments added to their engagement with the categories of boats and marine vessels to find a 'structure that is common to more than one world to make them recognizable' (Bowker \& Star, 1999). They are all well aware that the outcome of this discussion will have a lasting effect on future publications and use of the wiki. It will also determine if this local history wiki becomes interesting for coastal historians and historians of coastal culture. These concerns with the growth of lokalhistoriewiki.no are shared between the wiki administrators, supervisors and contributors and they have a common goal of providing support for multiple forms of knowledge. Meanwhile their attachments to this endeavour are different, and are rooted in different conventions of practice behind their engagement with the lokalhistoriewiki.no project.

The cultural heritage field is characterized by a high level of community initiatives and involvement, long based on participatory knowledge infrastructures where political and social configurations of the community are constantly shifting and hard to grasp (Crook, 2007, 2010). A consensus-based approach to community engagement within cultural heritage has ensured a continued misrecognition of the fact that representations of memories can have the powerful effects of hierarchies, not least in the range of possible stakeholders in the community (Waterton \& Watson, 2010). We observe that the local historians involved in lokalhistoriewiki.no 
see the wiki platforms as an opportunity for a new social and technical platform where issues of authenticity, trust and power may be negotiated openly (Waterton E, 2010), and power-laden hierarchies neutralized. The attachment of the local historians to openness therefore involves keeping the wiki inclusive for multiple historical perspectives, and to build a platform for the community to grow. While their attachments open up to the community of local history, they collide with other attachments to wiki platforms and practices.

The content creation of wiki-spaces is always an incomplete and continuing process relying on constructive participation by the community (Bruns, 2008). From our story we see how this incomplete and continuing process is based on negotiation between local historians and the technical preferences of the wiki administrator that seems to end up with a question of priority of attachments and authority to find solution. The main attachment for wiki administrators is a concern to keep the number of categories below a complexity threshold. The administrator's concerns are directed by basic principles of hierarchical structuring of wiki content, as well as conventions, guidelines and templates for ordering knowledge in wikis to secure simplicity and searchability (van der Velden, 2013). The attachments of the wiki-administrator are related to the organization of the body of knowledge and how the articles relate to each other in the wiki structure, and categorizing structures as a vehicle for connecting the community. Thus, the orderliness of the wiki is a central attachment for the wiki administrator, and he seems less concerned about the quality of the wiki as a matter of giving room for multiple knowledges. The attachments of wiki administrators, therefore, are about commitment to the hierarchical structure of the wiki and the conventions provided by the Wikipedia community.

This is at odds with the concerns that contributors and supervisors from the local historian community share. Their attachment to the wiki is that the category system should fit with and connect the diverging, multiple disciplinary communities that engage with boats and marine vessels. Their rationale for this is to keep a high disciplinary level of categorizing in the wiki structure, and to align well with the ones active among local as well as marine historians. The disciplinary concerns introduce a complexity related to the historical development of boats and vessels, as well as concerns of formal and informal categories. While the open structure of the wiki platform in theory provides the technological means for negotiations across communities, making visible multiple contributions to local history, giving access to participation in discussions from multiple viewpoints, they are still dependent on aligning these with the technical structure of the wiki. Solving the dilemmas of establishing a category structure that is on one hand both technically simple and easy to use for all and on the other hand precise enough to make the wiki suitable for professional knowledge building, it seems priority is given to a technical solution. The disciplinary and professional concerns of the local historians have to align with the ones of the wiki administration.

The story tells how infrastructuring and wiki policies involve negotiations between these diverse attachments. Attachments to developing a neat and simple hierarchical structure that may be used by many collide with attachments to making room for the scope of cultural heritage knowledge and the multiple understandings of boats and marine vessels that connect coastal historians, marine historians and experts of traditional coastal knowledge.

\section{Discussion}

Our stories describe two different knowledge infrastructuring processes towards participatory cultural heritage. The Swedish project intended to create citizen-centric digital services on archival material in a public institution in line with the PSI directive. The lokalhistoriewiki.no project in Norway involves infrastructuring in a non-governmental setting heading towards communitybased development of local history writing. While both stories relate to processes of infrastructuring aimed at fitting with contemporary ideas and directives of crowdsourced, participatory and open cultural heritage served by technologies, they differ in their approach from above and below. They tell also of different phases of knowl- 
edge infrastructuring. The first case describes the start-up phase of deciding how to design future e-services. The second case focuses on knowledge infrastructuring when the work is ongoing. The stories also differ in relation to the materiality of the technology involved: the archivists are relating their design-oriented endeavours to existing technical archival infrastructures, while the local historians have made a decision to use the readymade technical platform of wiki and configure this to their needs. Thus, material technology plays different roles in the knowledge infrastructuring in the two stories.

But there are also similarities; both stories involve people with great engagement with and passion for cultural heritage: the present, past, and future of cultural heritage understanding and its relevance to society. The two stories also make visible the inherent conflicts that arise when existing conceptions of openness and democratic cultural heritage institutions are contested by technological developments that introduce more radical forms of participation. Archives have always been 'open' in that it is possible to visit and use the physical archival holdings. This openness is taken for granted as part of archives' raison d'être. But openness means something slightly different in analogue contexts of managing archival holdings compared to openness in digital infrastructures and practices which brings multiple new dimensions and meanings. The local-historian community is encountering a similar change. Their work has been related to writing paperbased books and journals distributed through local historical societies or by The Norwegian Institute of Local history. The access to local history source material as well as the open distribution of local historical production is imbricated with the collaborative and value laden social space of the community. These social aspects of local historical material bring the raison d'être for local historians, and maybe even more for the amateur local history expert. Thus, it is crucial for both cases, as for every memory institution, to address, problematize and sort out the complexity of openness described in policy documents in relation to local practices and their social and material scales.

We have focused on how attachments to openness and public involvement influence infrastructuring in a formal institutional context and in an informal context of an NGO. Our focus on attachments has been related to aspects of knowledge that are both sources and resources brought under scrutiny in knowledge infrastructuring processes. Our stories show that both the open archive and the wiki are objects of study that 'arrive', rather than objects that are performed (Gomart \& Hennion, 1999). The Swedish archivists started with designing crowdsourcing possibilities and arrived at focusing on linked open data. The radical understanding of openness came with too many attachments to the unpredictability of crowdsourcing. These were related to control of archival content and quality in accordance with archival provenance principles and concerns with orderliness. These are concerns developed over time, and situated in daily practices that guarantee the trustworthiness and quality of archival information. The story tells how their situated practice of provenance principle collided with principles of crowdsourcing, and how linked data was found as a relevant solution for archival openness. The reasons for these attachments were hard to grasp, and it was hard to understand the scale and scope of consequences the archivists saw of crowdsourcing. There are many understandings and misunderstandings of crowdsourcing in the cultural heritage sector. These are often limited to instrumental understandings of crowdsourcing as an instrument enabling better delivery of content to end users. A re-conceptualisation could for example be in understanding crowdsourcing as an opportunity to actually engage users in public memory in meaningful ways, and as the "fundamental reason that these digital collections exist in the first place" (Owens, 2013: 128).

The story of the Norwegian local historians collaborating with wiki administrators' depart from a context where crowdsourcing is already happening, and is perhaps an example of how practices of the open archive could have become. We see how this open crowdsourcing is a process of constant arriving, of constant negotiations of the categorization structure between technical and social considerations. The attachments of the wiki administrator are closely related to issues reminiscent of the archivists': orderliness, control and quality. In wiki terms, this is about techni- 
cally simple structure and categorization. These attachments that the wiki administrator connects to growing the wiki conflict with the social and political attachments of the local historians and the way they envision the wiki project bringing together multiple local history communities. By focusing on the diverging attachments at play, we see how one knowledge-infrastructuring process, aligning all actors to one shared and simple structure, collides with the other knowledge-infrastructuring process, making a structure that enrols multiple actors.

The analysis shows how applying attachments as an analytical tool requires a focus on the events in infrastructuring processes, rather than on the relation between agent and structure. Attachments have helped us to pay attention to infrastructuring as a process-in-the-making. In addition, the concept has made us capable of moving beyond intentions and causations to search for entities that do not belong to the vocabulary of action. It is this move that allows us to understand the subtle distinctions between the archivists and the wiki-historians. In both stories we see how attachments towards openness point to different conceptions of orderliness, quality and control. The knowledge infrastructuring in the archival case illustrates how attachments are closely related to situated knowledges (Haraway, 1988) that do not come to terms with radical principles of openness. The knowledge infrastructuring in the wiki case builds a priori on a version of radical openness but illustrates how different sets of attachments cause collision between wiki administrators and local historians. Consequently the two stories of attachments show how situated knowledges sometimes come up short in innovative infrastructuring processes, and may cause good arguments for resisting change or new opportunities for sharing and connecting information and resources.

We have shown how attachments give us access to the negotiations that run the risk to be invisible and not articulated in the policy implementation process. The challenge of tensions, opposition, resistance, work-arounds, and nonadoption of new knowledge infrastructures is not a new narrative in knowledge infrastructuring studies. However, we argue, that the concept of attachment has helped us to pay attention to how relations between past, present and future may sometimes bring contradiction between situated knowledges, the past and the envisioned future. For example policies such as the PSI directive are first and foremost focused on anticipated outcomes: the 'wants' and 'needs' they are expected to fulfil. But we argue that there is no straightforward way ahead.

Existing knowledge practices are sources for understanding the future and our story shows that attachment to contemporary practices and understandings of future scenarios are linked to the history of professional practices. By focusing on attachments we have identified that openness is understood in two ways: first, as a technical concern with 'Open data' or 'Open Software' which indicates that data should be freely accessible to everybody for any purpose, and without restrictions of control besides European and national privacy legislation, such as copyright or patents. This is a technical-administrative understanding of openness. Second, in cultural heritage institutions, openness also relates to 'how' the institution works, which may include the way the institution motivates and aligns multiple goals in collaborations with communities. This is a social understanding of openness. Both understandings are challenged by contemporary ideas of open data, crowdsourcing and emerging conceptions of future democratic institutions. The notion of attachment has given us a tool to identify entities, sources and resources of how these challenges activate situated knowledges that may go beyond articulation work, and include future orientations that are based in historical constituencies of practice but that have still not a developed language.

We started out by asking what attachment people in cultural heritage institutions have to infrastructures of digital heritage participation and open data, and how these are related to existing knowledge practices. We have found that the open data initiative challenges the cultural heritage sector, which has mainly concentrated on preservation, meaning 'taking care of', 'attending to' and 'safeguarding' archival collections. Consequently, openness or closeness seems to relate to knowledge practices of inclusion and exclusion of 
data, categories and the subsequent knowledge exchange with citizens. In innovations towards openness, these knowledge infrastructures are put under scrutiny, and various risks are attached to social dimensions of public involvement implicated in openness. We have seen how the existing knowledge structures and conventions of practice in archives have no room for attachments that require spaces of contestation (Barry, 2001) and do as a result collapse and bring ambivalence into innovative knowledge infrastructuring. 


\section{References}

Alsvik O (1993) Local history in Norway. The Norwegian Institute of Local History and Local History in Norway, Oslo: NLI. Available at: http://www.lokalhistorie. no/english/local-his.html (accessed: 15.09.2010).

Andersen KV (2006) E-government: Five Key Challenges for Management. The Electronic Journal of eGovernment 4(1):1-8.

Andersen KV, Grönlund Å, Moe C E \& Sein M K (2005) Introduction to the Special Issue Egovernment in Scandinavia. Scandinavian Journal of Information Systems 17(2): 3-10. Available at: https://pdfs.semanticscholar. org/9545/7c9e9f70c7d44dc3582ea0ce96e0df38131f.pdf (accessed: 8.11.2016)

Baker KS \& Millerand F (2007) Articulation Work Supporting Infrastructure Design: Coordination, Categorization, and Assessment in Practice. In: Proceedings of the $40^{\text {th }}$ Hawaii International Conference on System Sciences: 1-10.

Baker KS, Jackson SJ \& Wanetick JR (2005) Strategies supporting heterogeneous data and interdisciplinary collaboration: towards an ocean informatics environment. In: System Sciences, 2005. HICSS'05. Proceedings of the 38th Annual Hawaii International Conference on. IEEE: 219b-219b.

Barry A (2001) Political Machines: Governing a Technological Society. London: The Athlone Press.

Björgvinsson E (2014) The Making of Cultural Commons: Nasty Old Film Distribution and Funding. In: Ehn P, Nilsson EN \& Topgaard R (eds) Making Futures: Marginal Notes on Innovation, Design, and Democracy. Cambridge, Massachusetts: MIT Press.

Björgvinsson E, Ehn P \& Hillgren PA (2012) Design Things and Design Thinking: Contemporary Participatory Design Challenges. Design Issues 28(3): 101-116.

Bossen C \& Markussen R (2010) Infrastructuring and Ordering Devices in Health Care: Medication Plans and Practices on a Hospital Ward. Computer Supported Cooperative Work 19(6): 615-637.

Botero A, Paterson A, Saad-Sulonen J (eds) (2012) Towards peer production in public services: Cases from Finland. Aalto University publication series Crossover 15/2012 Helsinki: Finland.

Bowker G (2005) Memory Practices in the Sciences. Cambridge, Massachusetts: MIT Press.

Bowker G, Baker K, Millerand F \& Ribes D (2010) Toward Information Infrastructure Studies: Ways of Knowing in a Networked Environment. In: Hunsinger J et al. (eds) International Handbook of Internet Research. Dordrecht: Springer, 97-117.

Bowker G (1994) Information Mythology and Infrastructure. In: Lisa Bud-Frierman (ed): Information Acumen: The Understanding and Use of Knowledge in Modern Business. London: Routledge, 231-247.

Bowker G \& Star SL (1999) Sorting Things out Classification and its Consequences. Cambridge, MA: MIT Press.

Braudel F (1958) La longue duree, Annales E.S.C 4, 725-753

Bruns A (2008) Blogs Wikipedia, Second Life and Beyond From Production to Produsage. New York: Peter Lang.

Bødker K, Kensing F \& Simonsen J (2004) Participatory IT Design. Designing for Business and Workplace Realities. Massachusetts: MIT Press.

COM (2010) 743 Final The European eGovernment Action Plan 2011-2015 Harnessing ICT to promote smart sustainable \& innovative Government. Available at: http://eur-lex.europa. eu/LexUriServ/LexUriServdo?ur $\mathrm{i}=$ COM:2010:0743:FIN:EN:PDF (accessed: 8.11.2016).

COM (2011a) 877 Final Proposal for a Directive of the European Parliament and of the Council Amending Directive 2003/98/Ec on Re-Use of Public Sector Information.

COM (2011b) 882 Final Communication from the Commission to the European Parliament the Council the European Economic and Social Committee and the Committee of the Regions. 
Crook E (2007) Museums and Community Ideals Issues and Challenges. Milton Park: Routledge.

Crook E (2010) The Politics of Community Heritage: Motivations, Authority and Control. International Journal of Heritage Studies 16(1-2): 16-29.

de Jong T\& Ferguson-Hessler MGM (1996) Types and Qualities of Knowledge. Educational Psychologist 31(2): 105-113.

Directive 2003/98/EC (2003) Directive 2003/98/Ec of the European Parliament and of the Council of November 2003 on Re-Use of Public Sector Information.

Dollar C M (1992) Archival theory and information technologies: The impact of Information Technologies on Archival Principles and Methods. University of Macerata, Macerata

Economics and the Common(s) (2013) Economics and the Common(s): From seed form to core paradigm. A report on an international conference on the future of the commons organized by the Heinrich Böll Foundation, Commons Strategies Group, Charles Léopold Mayer Foundation, and Remix the Commons. Available at: https://www.boell.de/sites/default/files/ecc_report_final.pdf (accessed: 8.11.2016).

Edwards P N, Jackson S J, Chalmers MK, Bowker G C, Borgman C L, Ribes D, Burton M \& Calvert S (2013) Knowledge Infrastructures: Intellectual Frameworks and Research Challenges. Ann Arbor: Deep Blue. Available at: http://hdl handle net/2027 42/97552 (accessed: 10.10.2015).

Edwards P N (2010) A Vast Machine: Computer Models, Climate Data and the Politics of Global Warming. Cambridge, MA: MIT Press.

Edwards PN, Jackson S J, Bowker G C, Williams R (2009) Introduction: An Agenda for Infrastructure Studies. Journal of the Association for Information Systems, 10; special issue, 364-374

Ehn P (2008) Participation in Design Things. Proceedings of Participatory Design Conference 2008, Indiana Bloomington, USA, September 30-October 42008.

Fujimura J (1987) Constructing ‘Do-Able’ Problems in Cancer Research: Articulating Alignment. Social Studies of Science 17: 257-293.

Gauld R Grey A \& McComb S (2009) How Responsive Is Egovernment? Evidence from Australia and New Zealand Government. Information Quarterly 26(1): 69-74

Grinter R (1996) Supporting Articulation Work Using Software Configuration Managements System. Computer Supported Collaborative Work: The Journal of Collaborative Computing 5:447-465.

Greimas AJ \& Courtes J (1986) Sémiotique II: Dictionnaire raisonné de la théorie du langage. Hachette, Paris.

Gomart E \& Hennion A (1999) A Sociology of Attachment: Music Amateurs, Drug Users. In: Law J \& Hassard J (eds) Actor Network Theory and After. Oxford: Blackwell, 220-47.

Grönlund Å \& Ranerup A (eds) (2001) Elektronisk Förvaltning, Elektronisk Demokrati. Visioner Verklighet Vidareutveckling. Lund: Studentlitteratur.

Halonen A (2012) Being Open About Data Analysis of the UK open data policies and applicability of open data. The Finnish Institute in London. Available at: http://finnishinstitute.cdn.coucouapp.com/media/ W1 siZilsljIwMTYvMDgvMjUvMDkvMzgvMjEvZGQyOGQ5MTUtY2Q4YSO0N2U0LWEyZTAtM2FiOWUxN2M0Njc2L2JlaW5nIG9wZW4gYWJvdXQgZGF0YS5wZGYiXV0/being\%20open\%20about\%20data. pdf?sha=cad600352a6ffb0b (accessed 12.11.2016)

Haraway D (1988) Situated Knowledges: The Science Question in Feminism and the Privilege of Partial Perspective. Feminist Studies 14(3): 575-599.

Hennion A (2012) Attachments: A Pragmatist View Of What Holds Us. In: The First European Pragmatist Conference, Roma 19-21 September 2012.

Hellberg AS \& Hedström K (2014) The Story of the Six Myth of Open Data and Open Government. Transforming Government: People, Process and Policy 9(1): 35-51. 
Hess C (2008) Mapping the New Commons. In: Governing Shared Resources: Connecting Local Experience to Global Challenges. Presented at the 12th Biennial Conference of the International Association for the Study of the Commons. University of Gloucestershire, England. Available at: http://dx.doi.org/10.2139/ ssrn.1356835 (accessed: 8.11.2016).

Hine C (2000) Virtual Ethnography. London, Thousand Oaks, New Delhi: SAGE.

Hine C (ed) (2005) Virtual Methods Issues in Social Research on the Internet. Oxford, New York: BERG.

Hillgren PA, Seravalli A \& Emilson A (2011) Prototyping and Infrastructuring in Design for Social Innovation. CoDesign 7(3-4): 169-183.

Holdgaard N \& Klastrup L (2014) Between Control and Creativity: Challenging Co-creation and Social Media Use in a Museum Context. Digital Creativity 25(3): 190-202.

Karasti H (2014) Infrastructuring in Participatory Design. In: Proceedings of Participatory Design Conference 2014, Windhoek Namibia 6-10 October 2014.

Karasti H (2001) Increasing sensitivity towards everyday work practice in system design. Dissertation, University of Oulu.

Karasti H (2003) Can film developers be(come) technology developers? Reflections on gendered expertise and participation in system design. In: Mörtberg C, Elovaara P \& Lundgren A (eds) How do we make a difference: information technology, transnational democracy and gender. Luleå: Luleå University of Technology, 20-49.

Karasti H \& Baker K S (2004) Infrastructuring for the Long-Term: Ecological Information Management. In: Proceedings of HICSS'37. Hawaii, USA, January 5- 8, 2004, 10.

Karasti H \& Syrjänen AL (2004) Artful Infrastructuring in two Cases of Community PD. In: Proceedings of Participatory Design Conference 2004, 20-30. Artful Integration: Interweaving Media, Materials and Practices. Toronto, Canada, July 27-31, 2004. ACM Press, 20-30.

Kellogg KC, Orlikowski W J \& Yates J (2006) Life in the Trading Zone: Structuring Coordination across Boundaries in Postbureaucratic Organizations. Organization Science 17(1): 22-44.

Lathrop D \& Ruma L (eds) (2010) Open Government - Collaboration Transparency and Participation in Practice. Sebastopol: O’Reilly Media Inc.

Latour B (1999 [2004]) Politics of Nature: How to Bring the Sciences into Democracy. Cambridge, MA: Harvard University Press.

Le Dantec C A \& DiSalvo C (2013) Infrastructuring and the formation of publics in participatory design. Social Studies of Science 43(2): 241-264.

Lessig L (2004) Free Culture: How Big Media Uses Technology and the Law to Lock Down Culture and Control Creativity. New York: Penguin Press.

Marres N (2007) The Issues Deserve More Credit: Pragmatist Contributions to the Study of Public Involvement in Controversy. Social Studies of Science 37: 759-780

Mörtberg C, Bratteig T, Wagner I, Stuedahl D \& Morrison A (2010) Methods that matter in digital design research. In: Wagner, Bratteteig, Stuedahl (eds) Exploring Digital Design. Multi-disciplinary design practices. London: Springer verlag, 105-147.

Oomen J \& Arroyo L (2011) Crowdsourcing in the cultural heritage domain: opportunities and challenges. Paper presented at 5th International Conference on Communities \& Technologies in Brisbane, Australia. Available at: http://dl.acm.org/citation.cfm?id=2103373\&CFID=864331598\&CFTOKEN=15293815 (accessed: 12.11.2016).

Owens T (2013) Digital Cultural Heritage and the Crowd. Curator: The Museum Journal 56(1): 121-130. 
Parker R \& Bradley L (2000) Organizational Culture in the Public Sector: Evidence from Six Organizations. International Journal of Public Sector Management 13(2): 125-141.

Perkin C (2010) Beyond the Rhetoric: Negotiating the Politics and Realizing the Potential of CommunityDriven Heritage Engagement. International Journal of Heritage Studies 16(1): 107-122.

Pipek V \& Wulf V (2009) Infrastructuring: Toward an Integrated Perspective on the Design and Use of Information. Technology Journal of the Association for Information Systems 10(5): Article 1.

PSI DIRECTIVE 2013/37/EU (2013) DIRECTIVE 2013/37/EU OF THE EUROPEAN PARLIAMENT AND OF THE COUNCIL of 26 June 2013 amending Directive 2003/98/EC on the re-use of public sector information http://ec europa eu/digital-agenda/en/european-legislation-reuse-public-sector-information (accessed 2014-02-17)

Ribes D \& Finholt TA (2009) The Long Now of Technology Infrastructure: Articulating Tensions in Development. Journal of the Association for Information Systems 10(5): Article 5. Available at: http://aisel.aisnet.org/ jais/vol10/iss5/5 (accessed: 8.11.2016).

Runardotter, M (2011) Organizational cooperation for cultural heritage-A viable systems approach. System Research and Behavioral Science (28): 77-90. doi:10.1002/sres.1047

Runardotter M, Mirijamdotter A \& Mörtberg C (2011) The Changing Nature of Archives - Whose Responsibility? Electronic Journal on eGovernment 9(1): 68-78.

Røssaak E (ed) (2011) The Archive in Motion: New Conceptions of the Archive in Contemporary Thought and New Media Practice. Oslo: Studies from the National Library of Norway NOVUS, 11-29.

Sefyrin J \& Mörtberg C (2009) "We Do Not Talk About This” - Problematical Silences in E-government. Electronic Journal of eGovernment 7(3): 259-270.

Schmidt K \& Bannon L (1992) Taking CSCW seriously: Supporting Articulation Work. Computer Supported Cooperative Work 1(1): 7-40.

Star S L (2010) This is Not a Boundary Object: Reflections on the Origin of a Concept. Science, Technology \& Human Values 35(5): 601-617.

Star S L \& Bowker G C (2002) How to infrastructure? In: L A Lievrouw \& S L Livingstone (eds) The Handbook of New Media. Social Shaping and Consequences of ICTs. London: Sage Publications, 151-162.

Star S L \& Ruhleder K (1994) Steps Towards an Ecology of Infrastructure: Complex Problems in Design and Access for Large-Scale Collaborative Systems. In: Proceedings of Computer Supported Cooperative Work (CSCW) Conference, Chapel Hill, North Carolina USA, October 22-26 1994: 253-264.

Star S L \& Ruhleder K (1996) Steps toward an Ecology of Infrastructure: Borderlands of Design and Access for Large Information Spaces. Information Systems Research 7(1): 111-134.

Stevens M, Flinn A \& Shepherd E (2010) New Frameworks for Community Engagement in the Archive Sector: from Handling over to Handing on. International Journal of Heritage Studies 16(1): 50-76.

Stoltzfus K (2005) Motivations for Implementing E-Government: An Investigation of the Global Phenomenon. In: Proceedings of National conference on digital government research, Atlanta, Georgia: 333-338.

Stuedahl D (2009) Digital Cultural Heritage Engagement - A New Research Field for Ethnology. Ethnologia Scandinavica 39: 67-81.

Stuedahl D (2011) Social Media and Community Involvements in Museums. A case study of a local history wiki community. Nordisk Museologi 2011(1): 3-14.

Strauss A (1993) Continual Permutations of Action. New York: Aldine De Gruyter.

van der Velden M (2013) Decentering Design: Wikipedia and Indigenous Knowledge. International Journal of Human-Computer Interaction 29(4): 308-316. 
Van Passel E \& Rigole J (2014) Fictional institutions and institutional frictions: creative approaches to open GLAMs. Digital Creativity 25(3): 203-211.

Vickery G (2011) Review of Recent Studies on Psi Re-Use and Related Market Developments 2011 Available at: https://www.nsgic.org/public_resources/Vickery.pdf (accessed 31.5.2012)

Waterton C (2010) Experimenting with the Archive: STS-ers as Analysts and Co-constructors of Databases and Other Archival Forms. Science Technology \& Human Values 35(5): 645-676.

Waterton E (2010) The Advent of New Digital Technologies. Museum Management and Curatorship 25(1): 5-11.

Waterton E \& Watson S (eds) (2010) Heritage and community engagement: collaboration or contestation? Routledge: London.

\section{Notes}

1 YEAH Project description Final Feb. 2012

2 Meeting notes 2012-01-18

3 Meeting notes 2012-02-02; Meeting notes 2012-02-20

4 Meeting notes 2012-03-1; Meeting notes 2012-03-26

$5 \quad$ Meeting notes 2012-04-24/25

6 Meeting notes 2012-10-24/25

$7 \quad$ Meeting notes 2012-06-27

8 Meeting notes 2012-09-04

9 Meeting notes 2013-03-25/26

10 The Handbook is available at: http://pure.Itu.se/portal/files/96261604/YEAH_Handbook_ ver_1_1_20140506.pdf (accessed: 14.11.2016). 